Article

\title{
Forest Maintenance Practices and Wood Energy Alternatives to Increase Uses of Forest Resources in a Local Initiative in Nishiwaga, Iwate, Japan
}

\author{
Takashi Hayashi $^{1, *}$, Daisuke Sawauchi ${ }^{2}$ and Daisuke Kunii ${ }^{1}$ \\ 1 Policy Research Institute, Ministry of Agriculture, Forestry and Fisheries, 3-1-1, Kasumigaseki, \\ Chiyoda-ku, Tokyo 100-0013, Japan; dsk921@affrc.go.jp \\ 2 Research Faculty of Agriculture, Hokkaido University, Kita 9, Nishi 9, Kita-ku, Sapporo, \\ Hokkaido 060-0809, Japan; dsawa@agecon.agr.hokudai.ac.jp \\ * Correspondence: th8841@affrc.go.jp; Tel.: +81-3-6737-9082
}

Received: 1 September 2017; Accepted: 25 October 2017; Published: 26 October 2017

\begin{abstract}
This study assesses the impact of wood energy use under underutilized conditions of wood resources: the impact on promotion of forest maintenance practices (FMPs), user costs, and local economies, using the case of a local initiative in Nishiwaga, Iwate, Japan. We conducted two main analyses: resource and economic assessment. For resource assessment, we investigate whether wood supply from FMP residue is sufficient to sustainably satisfy new demand created by a local initiative in Nishiwaga, and in how much forest area can FMPs be performed to satisfy the demand. These questions are analyzed by linear programming. Regarding economic assessment, we investigate whether replacement of fossil fuel by wood energy brings economic benefit to a user and local economy using input-output analysis. Our overall findings demonstrated that the use of wood energy under underutilized situations can lead to an increase of implementations of FMPs and of domestic wood resource supplies from a short-term perspective that comes from residues of the FMPs. We also found that wood energy consumption introduces co-benefits in terms of reduced heating costs for users and a larger economic impact on the local economy than fossil fuel.
\end{abstract}

Keywords: forest maintenance practice; wood energy; underutilization; thinned trees; sustainable wood resource; Japan

\section{Introduction}

Among various types of biomass, wood resource is the most anticipated biomass in Japan. After World War II, large-scale afforestation was implemented nationwide [1], and currently forest volume amounts to 4.9 billion $\mathrm{m}^{3}$, and continues to increase [2]. However, since investments in silviculture were not profitable anymore, forest owners reduced their labor input and eventually abandoned their forests, even though, by the 1990s, most of the plantation trees had grown to the point that they required thinning. This resulted in rapid decrease in domestic supply and overstock of low quality wood resources. This phenomenon can be seen nationwide and the Japanese government must address the problem of underutilization of domestic wood [3].

One option to improve the concerns is to implement proper forest maintenance practices (FMPs) such as thinning and replanting [4]. FMPs not only directly promote wood supplies by thinned trees but also indirectly contribute to increase stable supplies by making forests sound and vital in the long run. Figure 1 shows the condition of two different forests. Both forests are abandoned and not used for commercial logging. However, the left forest continues to maintain minimal FMPs, although practices to enhance commercial value of logging such as pruning and understory removal have not been done. The right forest has not implemented any practices at all. This condition causes some problems: 
the trees easily fall down by heavy rain, strong wind and typhoons. Therefore, FMPs, at least minimum ones, are necessary for planted forest in Japan. Once wood residue, which is generated by FMPs, is utilized, FMPs will further accelerate. Energy use is one of the easiest and the most anticipated options for the utilization of wood residue. It is important to assess the impact of wood energy on the promotion of FMPs.

From the viewpoint of energy policy, the Japanese government is currently promoting renewable energy [5]. The share of renewable electric power increased to $14.8 \%$ in 2016, among which biomass is only a few percent [6]. If the abandoned wood residue were utilized as an energy source, it can replace a massive amount of fossil fuel and contribute to climate change mitigation. In this manner, not only in forestry policy but also in energy and environmental policies, the government regards implementing proper FMPs as one of the main purposes for wood energy utilization. Although these policies are made at national level, decisions of implementation of FMPs are made at local level. Additionally, use of wood energy is also expected to produce sound impacts on local economies by promoting local economic activities [7]. For the sustainable utilization of wood resources, such side effects must also be assessed at local level as well.
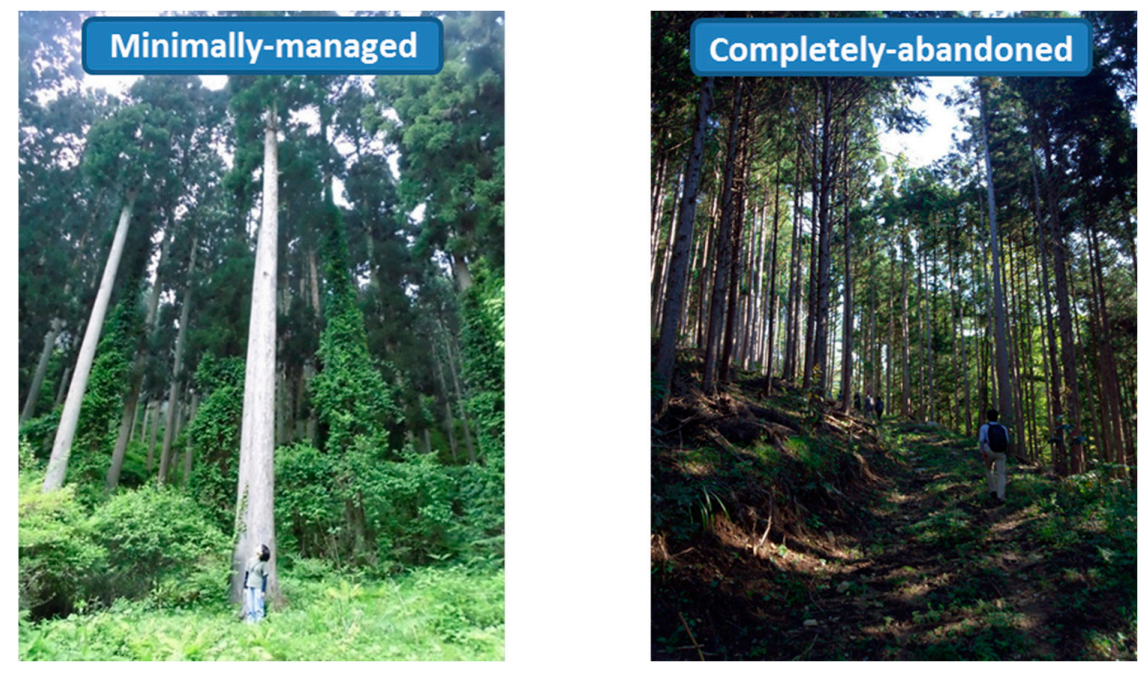

Figure 1. The condition of: minimally-managed forest (left); and completely-abandoned forest (right). As both forests are not used for commercial logging for long time, it is far from commercially well-managed forest. However, in the left forest, minimum FMPs have been conducted. On the other hand, in the completely-abandoned forest, no FMPs have not been conducted, thus it has dense and small diameter trees, with many knots, and little understory vegetation.

Since the overuse of biomass draws much attention in the sustainability context $[8,9]$, the underutilization issue is often overlooked. Overstocked wood resources are dealt with in some studies [10-12], but the issue is quite locally specific; its causes and impacts depend on locality, and initiatives in Japan are not dealt with in these studies. In addition, these studies do not assess multi-aspect impacts such as resource utilization and economic issues which include both impacts on user cost and local economy.

Using the case of a local initiative in Nishiwaga, Iwate, this study assesses the impact of wood energy use under underutilized conditions: the impact on FMP promotion, user costs, and local economies. Our study is conducted using a case of a wood-chip boiler installed in a municipal hospital in Nishiwaga, Iwate. The town, which is located in a mountainous area of northeast Japan (Figure 2), was established in 2005 by merging two municipalities: Yuda and Sawauchi. It has a population of about 6000 people in 2400 households. Ninety percent of its area is covered by forests, $4.5 \%$ of which are owned by the town government. Promoting FMPs is one of the town's largest concerns. 
In 2014, the town installed two wood-chip, $200 \mathrm{~kW}$ capacity boilers in its municipal hospital as part of a building reconstruction project. Hot water generated by the boilers is used for heating, the local water supply, and hydronic snowmelt systems. Although wood pellets might be a suitable choice at this scale, it needs more processing steps to be produced, and the cost becomes higher. This is why the local government did not choose the pellet option. As a result of newly installed wood-chip boiler in the hospital, additional demand of wood chips is created. The Nishiwaga Forest Owners' Cooperative (NFOC) is contracted to thin the town's forest and process the thinned trees into wood chips. To satisfy the demand, NFOC has to implement FPMs because production of wood-chips from thinned trees is a requirement of contract with the Nishwaga town government. Therefore, creation of new demand in the hospital automatically leads to increase in FMPs. Most of the wood chips used in the hospital come from the thinned forests owned by the town government; although wood chips are partly supplied from private forest, the amount is unsubstantial.

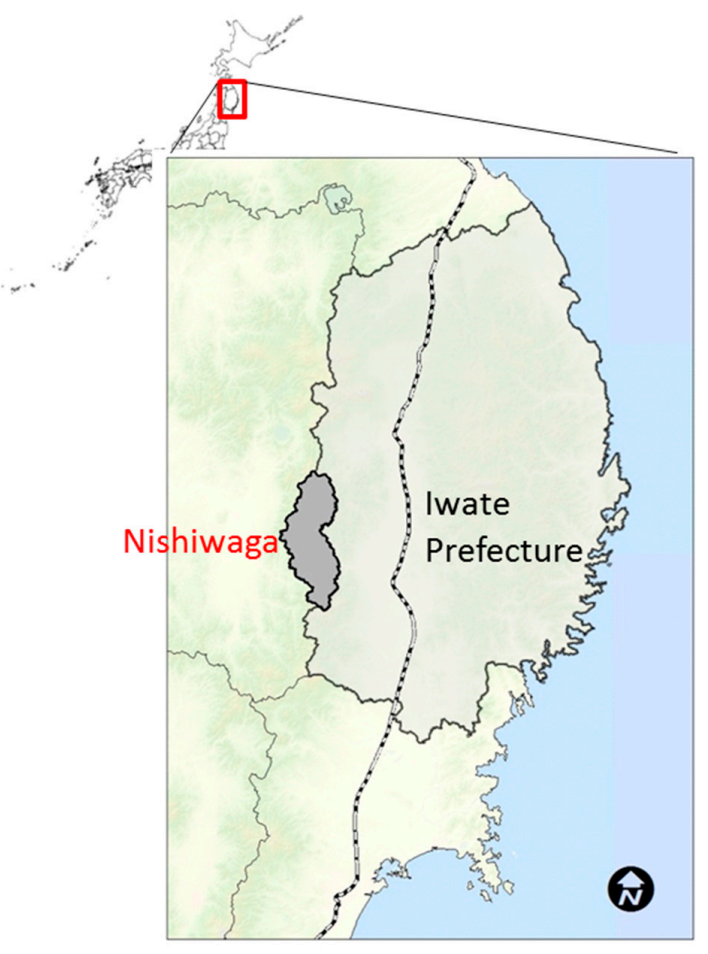

Figure 2. Location of study site.

\section{Methodologies}

\subsection{Analytical Framework}

To achieve the purposes of the study, we focus on the following four research questions:

Question 1: Is the wood supply from town forest sufficient to sustainably satisfy the new demand?

Question 2: In how much forest area can FMPs be performed based on the demand?

Question 3: How much are user costs reduced by wood energy compared to using fossil fuel?

Question 4: What is the difference between wood energy and fossil fuels in terms of positive economic impact on the local economy?

The first two questions relate to resource assessment, which deals with availability of wood resources caused by FMPs. Firstly, we investigate whether wood supply from town forest meets the wood-chip demand in the hospital (Question 1). Then, we calculate in how much area FMPs will be implemented to satisfy their increased demand for wood-chips (Question 2). Linear programming (LP) is applied to answer these questions. 
The third and fourth questions relate to the impact on economy: for the hospital and for local economy, respectively. The impact on the hospital is an essential factor to judge whether the hospital should install a wood-chip boiler. Furthermore, as promotion of local economy is one of the challenges of the town government, the impact on local economy should also be considered by town government. Input-output (IO) analysis is conducted to assess these economic impacts.

Figure 3 shows the relations of bioenergy, FMPs and system boundaries of this study. First, FMPs in this study are defined as the practices that are necessary for minimally maintaining forest condition such as thinning and replanting [4]. Practices to enhance commercial value of logging such as pruning, understory removal are not included. Among FMPs, the Japan government believes thinning is the most crucial practice [4]. By answering the above questions, policymakers can determine what kind of impact will be brought on FMPs, energy users, and local economies. To obtain this information, we conduct a "what if" analysis on the potential impact of the creation of wood demand for energy using the case of Nishiwaga. Such obtained information is critical to advance a sustainable supply of wood resources.

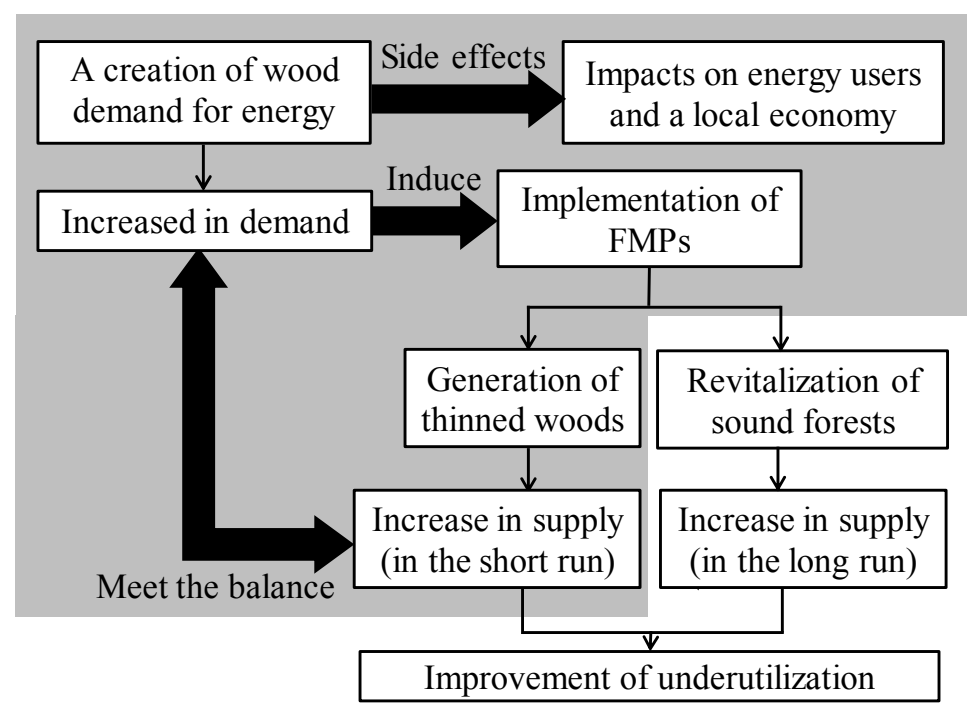

Figure 3. Schematic figure of wood energy, forest maintenance practices (FMPs), underutilization and sustainability. Grey area is system boundary of this study.

\subsection{Resource Assessment}

The flow of resource assessment is illustrated in Figure 4. For the assessment, we made some assumptions based on the actual situation and the maintenance of forests. First, the analysis only focuses on the town-owned forests (both exclusive and profit sharing) where Japanese cedars (Cryptomeria japonica D. Don) are planted. This is because Japanese cedar is the most common tree type in northeast Japan, and the town government is firstly going to implement FMPs in its own forests. Actually, the hospital obtained wood chips not only from town-owned forests but also from privatelyand nationally-owned forests. However, we failed to obtain data for national and private forests. In addition, for private forest, the amount is relatively unsubstantial. These are why our analysis only considers town-owned forests.

Second, $30 \%$ in volume of trees was thinned at tree ages of 25,35 , and 45 years based on a designated plan. The information was obtained by an interview with NFOC in 2015. Third, based on the town government's survey, $73 \%$ of the thinned trees are abandoned in forests due to low economic feasibility [13]. Fourth, we assume that $40 \%$ of the extracted trees are used for wood chips, and the rest is for construction based on an interview with NFOC. Wood chips are exclusively used for the hospital boilers. Fifth, we assume that trees grow constantly by an annual increase in volume based on 
information recorded in the 2012 forest registration data. However, this actually changes over time. In addition, after thinning has revitalized the forest, tree growth is promoted, and this thinning effect on tree growth is not considered in the analysis. Although some studies assume non-linear growth curve of trees [14], we approximate the yearly increase in the volume of trees to the constant level recorded in the forest registration data for the following two reasons. One is that we failed to obtain the appropriate mathematical model to estimate the growth curve of trees. Since tree growth heavily depends on such local conditions such as temperature, precipitation, and soil conditions, applying the growth rates of other regions is inappropriate. The other is that, to measure the total forest volume accurately, which relates to the long term supply analysis, is beyond the scope of this study (Figure 4). Finally, to answer Question 2, we assume that thinning is performed until the supply of wood chips meets the hospital demand. Therefore, the maximum wood-chip supply equals the hospital demand.

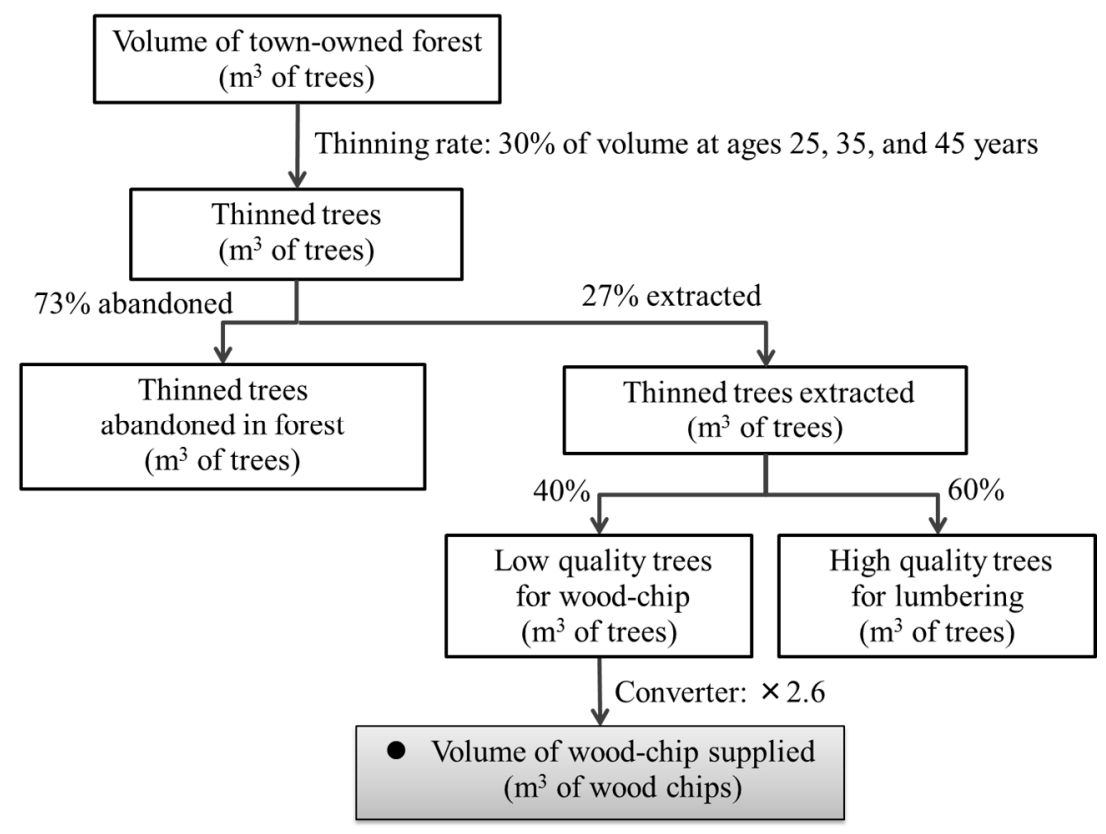

Figure 4. Block diagram of resource assessment.

We estimate the wood-chip supply from 2012 to 2030 so that its sustainability can also be considered. From interview with a town government officer, we identified the annual consumption of wood chips as $1442 \mathrm{~m}^{3}$. Among many forest compartments, the forest compartments to be thinned to guarantee the wood-chip supply are determined in the following manner. First, for the year when the volume of chip, which is produced from the trees at the appropriate age to be thinned, is expected to be less than $1442 \mathrm{~m}^{3}$, all of the forest compartments that need to be thinned will be thinned. Second, for the year when the volume of chip, which is produced from the trees at the designated age to be thinned, is expected to be more than $1442 \mathrm{~m}^{3}$, the forest compartments to be thinned are determined by simple LP to minimize the total cost (TC) of chip production. The mathematical formulation of the cost minimizing problem is shown as:

Minimize:

$$
T C=\sum\left(C_{t h}+C_{e x, i}+C_{t r, i}\right) S_{w, i}
$$

Subject to:

$$
\begin{gathered}
C_{t h}=1000 \\
C_{e x, i}=0.845 L_{y, i}+91.7 \exp ^{0.117 \theta_{i}}+1746
\end{gathered}
$$




$$
\begin{gathered}
C_{t r, i}=0.022 L_{t, i}+778 \\
\sum S_{w, i} \geq 1442
\end{gathered}
$$

where $S_{w, i}$ is the amount of wood-chip supply from the forest compartment $i\left(\mathrm{in} \mathrm{m}^{3}\right)$. $C_{t h}$ is the thinning cost per $\mathrm{m}^{3}$ of wood chips (in JPY $/ \mathrm{m}^{3}$ ). $C_{e x, i}$ and $C_{t r, i}$ are extraction and transportation cost per $\mathrm{m}^{3}$ of wood chips of the forest compartment $I$, respectively (in JPY $/ \mathrm{m}^{3}$ ). $\theta_{i}$ is the average degree of the slope in the forest compartment $i . L_{y, i}$ and $L_{t, i}$ are distance from the forest compartment $i$ to the nearest timber yards and the distance from the timber yards to the hospital via NFOC's factory, respectively (in $\mathrm{m}$ ). These cost equations are based on those in [15].

We obtained data on the forest age, volume, and tree types as well as the annual increase in volume from forest registration data provided by the town government. We also used geographical information system (GIS) data in our analysis. $\theta_{i}, L_{y, i}$, and $L_{t, i}$ were computed from these data. We solved the LP problem using Excel Visual Basic for Application (VBA).

By LP in supply-demand assessments, the forest compartments to be thinned are identified from the viewpoint of total cost minimization. In this assessment, we aggregated the area of these forest compartments to estimate the total area to be thinned.

\subsection{Economic Assessment}

For the cost assessment, we assumed that the thinned trees are processed into wood chips at NFOC's factory within the town and delivered to the hospital. The wood-chip cost is calculated based on the actual transaction price: $3500 \mathrm{JPY}$ per $\mathrm{m}^{3}$ (excluding value added tax (VAT)) between NFOC and the hospital in 2014. Price data were obtained by an interview with the town government in 2015. For fossil fuel, we referred to heavy oil whose average price in 2012 was $88.1 \mathrm{JPY} / \mathrm{m}^{3}$, including a $5 \%$ VAT [16], to estimate the fossil fuel cost. Note that, since April 2014, the VAT rate was raised from 5\% to $8 \%$. To guarantee consistent tax treatment, we added a 5\% VAT to the wood-chip price.

To assess the impact on the local economy, this study applied the same methodology as our previous study [17] and defined the following two impacts on the local economy: ratio of remaining expenditures out of total expenses and the induced economic impact on the economy. First, we calculated the remaining expenditures for both wood chips and fossil fuel and decomposed them into production values and margins (retail, wholesale, and transportation). Then, based on the expenditures, the induced economic impacts caused by increases in energy demand for both wood chips and fossil fuel were computed by IO analysis. Specifically, we compared the induced economic impact of 5.30 million JPY of wood-chip production and 11.91 million JPY of fossil fuel production; these figures are explained below in Section 3.3. IO analysis was conducted based on a 35-sector southern Iwate IO table for 2009, which was updated from 2005 version [18] by the authors' modification. We apply the same methodology with [19] to update the IO table, which assumes that input coefficients in 2009 did not change from 2005, and that only production value was updated to 2009 and distributed to intermediate input values to elaborate the $2009 \mathrm{IO}$ tables. Using the 2009 tables, induced effects are calculated by following equations:

$$
\begin{aligned}
\Delta X_{w} & =\left(I-\left(I-\bar{M}_{w}\right) A\right)^{-1}\left(I-\bar{M}_{w}\right) \Delta F l d_{w} \\
\Delta X_{f} & =\left(I-\left(I-\bar{M}_{f}\right) A\right)^{-1}\left(I-\bar{M}_{f}\right) \Delta F l d_{f}
\end{aligned}
$$

where $\Delta X$ is increase in local production, $A$ is input coefficients matrix, $\bar{M}$ is diagonalized import matrix, and $\Delta F l d$ is increase in local final demand. Suffixes $w$ and $f$ refer to wood chip and fossil fuel, respectively. Each $\Delta$ Fld is given by: 


$$
\begin{aligned}
\Delta F l d_{w} & =\Delta F_{w}\left(1-m w_{w}-m r_{w}-m t_{w}\right) \\
\Delta F l d_{f} & =\Delta F_{f}\left(1-m w_{f}-m r_{f}-m t_{f}\right)
\end{aligned}
$$

where $\Delta F$ is increase in final demand, $m c, m r$ and $m t$ are wholesale, retail and transport margins, respectively. Note that, since the original IO table is for the southern Iwate area (which includes Nishiwaga), the analysis results cover not only the Nishiwaga municipality but also a much broader area.

Data used for the analysis, such as $m w, m r$, and $m t$, were obtained from the national IO table of 2005 [20], and the matrices $\bar{M}$ and $A$ were obtained from the updated local IO table.

\section{Results}

\subsection{Supply-Demand Balance}

Regarding the supply-demand balance (Question 1), Figure 5 shows simulation results that estimate the annual wood-chip supply from 2012 to 2030. The amount of wood chips obtained from the thinning practice fluctuates from $479 \mathrm{~m}^{3}$ to $1442 \mathrm{~m}^{3}$, reflecting the forest area and volume that must be thinned each year. Note that we assume, in the LP process, thinning is performed until the supply meets the hospital's demand, and the maximum amount is limited to $1442 \mathrm{~m}^{3}$. This supply only satisfies the demand in 2016, 2018, and 2023, and, in other years, the supply will fail to meet the demand. These results reflect the assumption that only the town-owned forests are thinned to meet the wood-chip supply. In the town-owned forests, roughly three-quarters of the thinned trees are abandoned due to a lack of economic feasibility.

The assessment results of the supply-demand balance can be summarized as the answer to Question 1: although a wood-chip demand of $1442 \mathrm{~m}^{3}$ was created by the newly installed wood-chip boiler, in most years, such demand cannot be solely satisfied by the supply from the thinned trees in the town-owned forests. To satisfy it, more trees should be extracted than under the current situation.

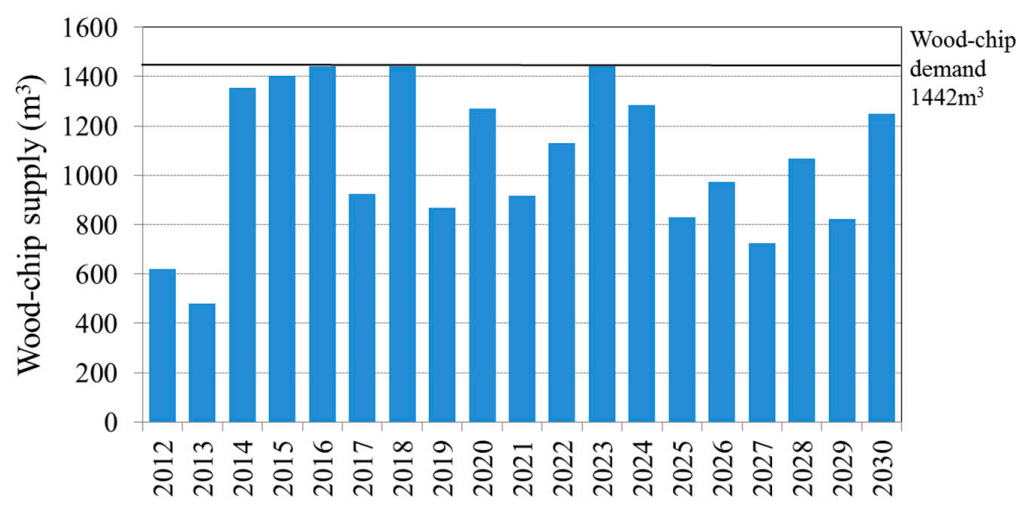

Figure 5. Estimated annual wood-chip supply from 2012 to 2030.

\subsection{Impact on FMPs}

The assessment results for the impact on FMPs are illustrated in Figure 6. The forests that must be thinned to satisfy the demand are shown in green bars; thinning can be performed in 60 to 85 hectares of forests each year. These figures are regarded as the potential to promote FMPs by newly created wood-chip demand in the hospital. If we focus on only town-owned forest, thinning can be performed in 17 to 88 hectares of the town-owned forests each year, illustrated by orange bars. In most years, thinning can be performed in all areas where it is needed due to the demand. However, since the demand is too large, the supply of wood chips from town-owned forests remains inadequate. Forests other than the town-owned ones must be thinned to meet the demand, and such areas are illustrated as 
blue bars; thinning can additionally be performed in 2 to 49 hectares of forests other than town-owned ones. A wide size range comes from the area fluctuations, and the volume that must be thinned every year. For 2016, 2018, and 2023, since the demand is not big enough to justify thinning all of the areas that need it, some town-owned forests where thinning is needed remain un-thinned. These areas are shown by red bars.

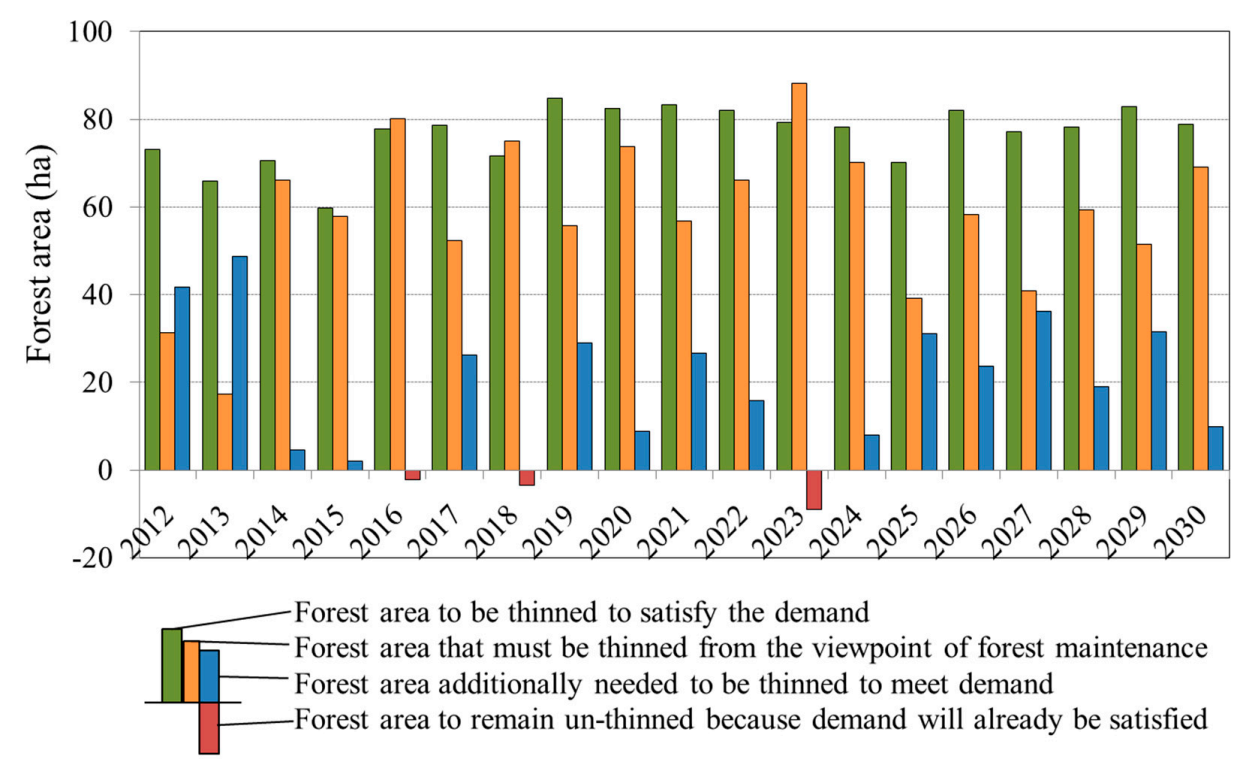

Figure 6. Estimated forest area thinning from 2012 to 2030: green bars show area where thinning must be done to satisfy the demand; orange bars show area where thinning will be needed from the viewpoint of forest maintenance; blue bars show area that must additionally be thinned to meet demand; and red bars show the area where no thinning will be done because the demand will have already been satisfied.

\subsection{Economic Impact on Cost Reduction}

In terms of the impact on the hospital's heating cost (Question 3), it annually budgets 5.30 million JPY for wood chips. Since $1442 \mathrm{~m}^{3}$ of wood chips equals $13.5 \mathrm{~m}^{3}$ calories of heavy oil, the hospital would have consumed this amount of fossil fuel if it had installed a fossil fuel boiler. At 2012 prices (88.1 JPY $/ \mathrm{m}^{3}$ [16]), the annual heating cost of fossil fuel would be 11.91 million JPY. The difference between the heating cost of the wood chips and the fossil fuel is 6.61 million JPY. Therefore, concerning cost effectiveness, wood chips have an advantage over fossil fuel. The price applied for the calculation of fossil fuel costs in 2012 was relatively high, and, currently, the price is much lower. However, even if the cost is calculated by the lower fossil fuel price (72.5 JPY / $\mathrm{m}^{3}$ : average price from March 2014 to February 2015 [16]), the annual fossil fuel cost is 9.8 million JPY, and wood chips still have an advantage. The fossil fuel cost equals the wood chips when fossil fuel prices fall to $39.2 \mathrm{JPY} / \mathrm{m}^{3}$, which is 45\% lower than the 2014 price. Therefore, to answer Question 3, the hospital reduced its heating costs by 6.61 million JPY by installing a wood-chip boiler instead of a fossil fuel one. However, note that this calculation does not consider the initial cost to install each boiler. This is because the cost of the wood-chip boiler was subsidized by the national government, and the fossil fuel boiler received no subsidy at all, complicating comparisons of initial cost.

\subsection{Economic Impact on Local Economies}

Regarding the economic impact on local economies, the results are shown in Figure 7. Since all of the wood chips are produced within the town, most of the expenditures spent on them remain in the town. According to our estimation, the remaining expenditures account for 4.96 million out 
of 5.30 million JPY of total expenditures, meaning that $93.6 \%$ remain in the town. The remaining wood-chip expenditures consist of domestic production and retail, wholesale, and transportation margins. All of these items were considered to be spent by the sectors within the town. On the other hand, since fossil fuel is imported, most of its expenditures, such as wholesale and transportation margins, flow out, and only 0.73 of the 11.91 million JPY of total expenditures $(6.1 \%)$ remain in the town.

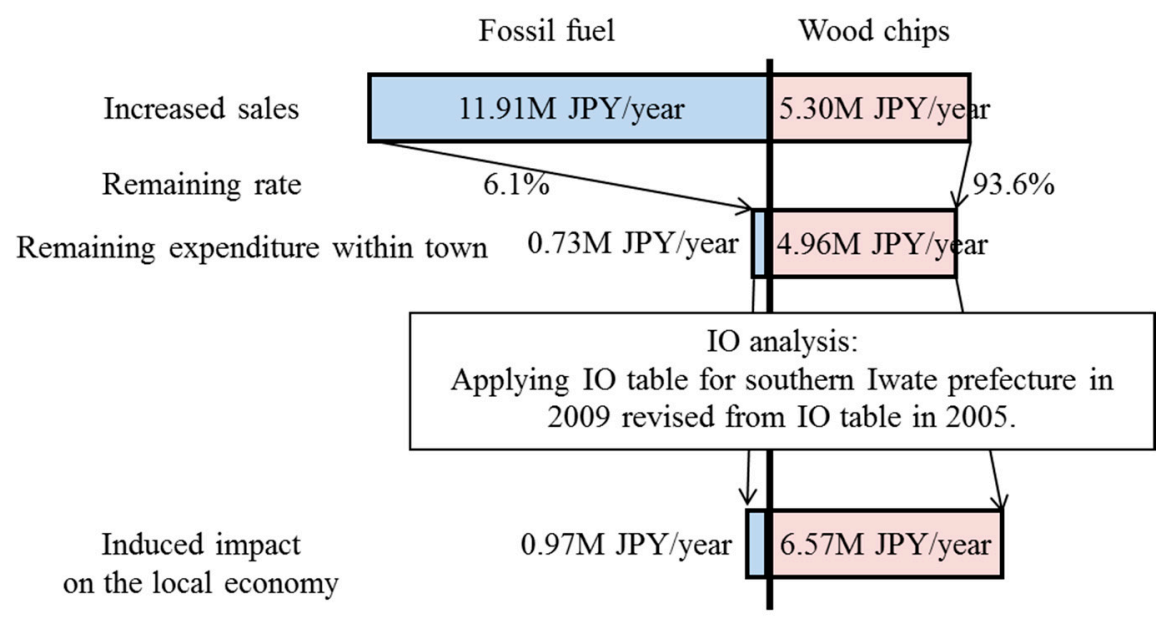

Figure 7. Impacts on local economy: the Left side of the figure shows the impact of fossil fuel, and right side shows that of wood chips.

The estimation results of the induced economic impacts are also shown in Figure 7. The induced economic impacts were calculated based on increases in the wood-chip demand of 5.30 million JPY and in the fossil fuel demand of 11.91 million JPY, assuming these expenditures were newly created by the additional demand of wood chips and fossil fuel in the hospital. The induced economic impacts brought by wood chips and fossil fuel, respectively, account for 6.57 and 0.97 million JPY, indicating that, even if the fossil fuel expenditures are much larger than those on wood chips, most of the former flow to other regions because fossil fuel is imported. On the other hand, since wood chips are produced domestically, most of the expenditures on them remain in the town and produce a larger induced economic impact on the local economy. Therefore, concerning the economic impact and the answer to Question 4, wood-chip consumption has a higher positive impact on the local economy than fossil fuels.

\section{Discussions}

Many studies on the assessment of wood energy supply and demand exist from various viewpoints, for example, the supply-demand balance [21], the optimal location of an energy facility [22], such multiple aspects as environmental and socio-economic impacts [23-26], cost and environmental impacts [27,28], sustainable logistics flow [29], and resource potential and economic feasibility [30]. Cambero and Sowlati [31] reviewed studies on the assessment of forest biomass supply chains from the economic, social, and environmental perspectives. However, as mentioned in Section 1, the impact assessment of wood energy to ease underutilized condition must also be related to FMPs. To the best of our knowledge, no previous study has assessed wood energy from this viewpoint. In addition, most previous studies that assessed the wood energy potential first estimated the availability of wood biomass for energy as a result of logging [23-35] in supply-oriented studies. However, from the viewpoint of mitigating underutilization, the information required is quite the opposite; how much forest area will be maintained by implementing a new wood energy project. In this context, the assessment should start from the demand of wood energy and estimate the forest area that can be maintained; this is demand-oriented analysis. 
The overall framework is illustrated in Figure 8. First, after obtaining the data of the demand of wood chips, we estimated from the forest registration data and the GIS data the expected amount of the thinned trees in each forest compartment and the supply cost, including the thinning and transportation cost of the thinned trees from the forest to the hospital via NFOC's factory where trees are processed into wood chips, according to cost estimation equations in a previous study [15]. Next, using the supply cost, the expected amount of thinned trees, and the annual wood-chip demand of the hospital, we identified which forest compartments should be thinned to minimize the total supply cost by LP and estimated the amount of wood-chip supply and the forest area to be thinned to answer Questions 1 and 2 posed in Section 2.1.

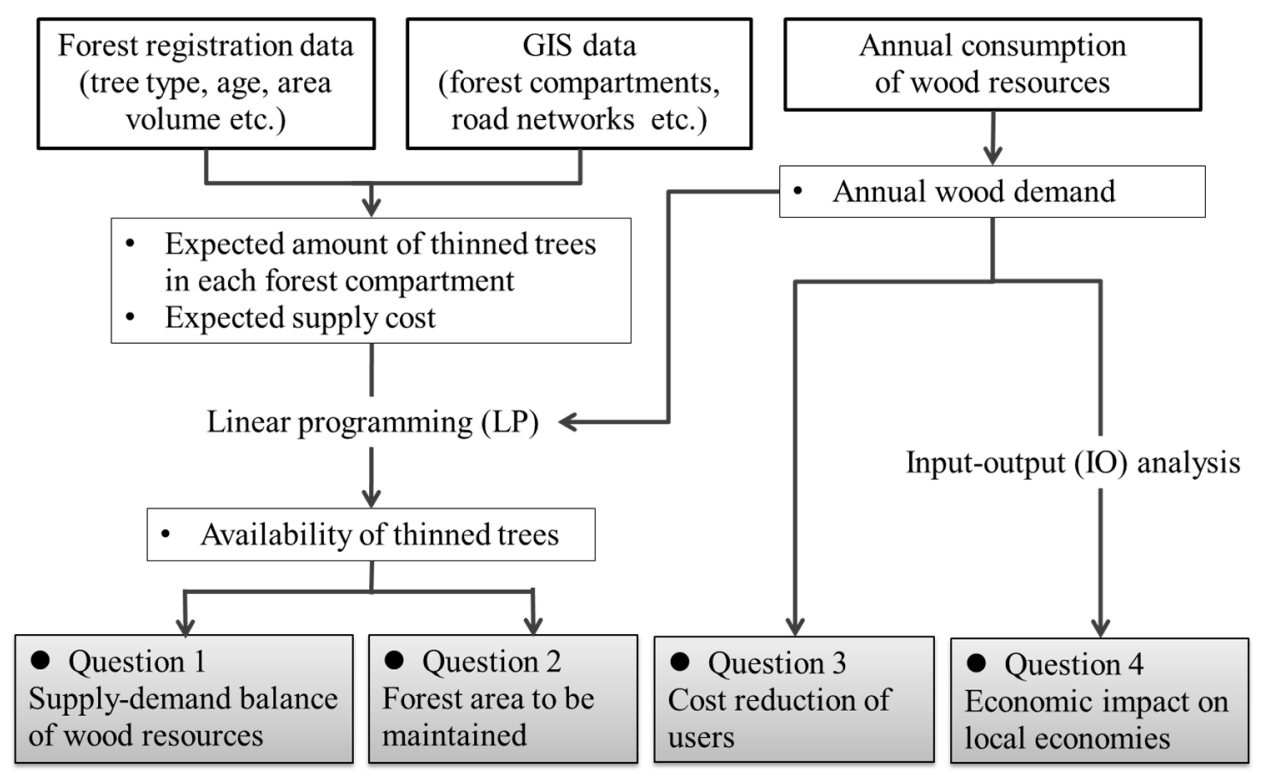

Figure 8. Framework of the assessment.

The next step assessed the economic impacts on both wood energy users and the local economy. Due to the introduction of wood energy, the economic impacts affect two different aspects: a reduction in user's heating costs, and a more vibrant local economy due to the increase in wood energy production. The former was analyzed by Question 3 and the latter by Question 4 . The economic assessments for Questions 3 and 4 were based on comparisons with fossil fuel, because when policymakers consider the installation of wood energy, they generally compare economic efficiency with fossil energy. However, if a user cuts costs by choosing wood energy instead of fossil fuel, this might reduce the cash flow in the local economy and negatively impact its economy. Since an inverse impact may be brought between a bioenergy user (micro) and local economic (macro) levels, we simultaneously analyzed these two different impacts. In the model, based on the wood-chip demand, the value of the replaced fossil fuel is estimated to assess the hospital's economic benefit. The value of the wood chips consumed by the hospital is used for the IO analysis to estimate the economic impact on the local economy.

In our case study, although the creation of wood energy demand promoted FMPs, the increase in the wood energy supply caused by such practices did not fully cover the new demand. This means that new demand has further potential to promote FMPs. The supply-demand balance results show that, in most years, FMPs can be performed not only in town-owned forests but also in other types of forests. Implementing them can increase the domestic wood supply in the short run by raising the thinned woods supply. As mentioned in Section 1, wood chips are also supplied from private forests, but that amount is relatively unsubstantial. Actually, local and national policymakers in Japan expect the promotion of FMPs in private forests. They believe that FMPs in town- or national-owned forests and a 
creation of new demand would accelerate FMPs and the use of privately owned forests. Governments should pave the way for the sustainable demand of thinned wood by promoting wood energy.

From an economic assessment, wood energy consumption brings co-benefits in terms of reduced heating costs for users (micro benefit) and a larger economic impact on local economies than fossil fuel (macro benefit). This means that these local initiatives not only impact on FMP promotion but also impact on both economies for users and localities. These economic impact results are interesting. On the one hand, users receive a benefit by reducing their heating expenditures compared to using fossil fuel, and local economies simultaneously receive a larger economic impact than fossil fuel, despite the reduction in user expenditures. Den Herder et al. [7] also conducted similar analysis on production cost and local value added. Their results are mostly consistent with ours, although some assumptions are different: they assume wood chips are processed outside the study site, while we assume that wood chips are processed in the locality.

As global business competition becomes more severe, cost reductions are required for efficient and effective firm management, even in small enterprises [36]. In some cases, local economies are beset by negative impacts, for instance, by replacing domestic products with mass produced ones and nationally or globally standardized products. However, our case suggests that cost reductions are not necessarily incompatible with positive economic impacts on local economies. Therefore, to achieve local sustainability, policymakers must seek co-benefits that accommodate both micro and macro benefits, as illustrated in our case.

One of the originality of the assessment in this study is that it focuses on underutilization issue. Although this study deals with a case in Japan, and the underutilized and overstocked condition of forest resources is observed in some other countries [37,38]. Another point is the multi-viewpoint assessment: impact on resource use, and economy including both micro and micro impacts. The other originality is that our analysis is demand-oriented. It starts from how much forest area will be maintained by implementing a new wood energy project. On the other hand, regarding weakness, our study has several limitations. For example, determining the better scenario in terms of the ecosystem services offered for the local communities by conducting the different scenarios on wood resource use is left for the future research. There is a challenge in an assumption for resource assessment: we assume the increase in the volume of trees is to be constant from 2012. This should be improved to achieve more precise results. In the analysis, no social factors were incorporated into it. Cambero and Sowlati [31] concluded that no studies have incorporated social factors into their assessments, implying that incorporating them is quite challenging. Nonetheless, social factors are indeed critical to ensure sustainable wood energy, particularly in rural areas where various factors other than economic ones play relatively important roles $[39,40]$. We recognize the need to include them in our assessment in the future and believe such an updated assessment can help achieve sustainability of wood resource.

\section{Conclusions}

Our overall findings demonstrated that the use of wood energy in underutilized situations can lead to an increase of FMP implementations and of domestic wood resource supplies from a short-term perspective that comes from residues of FMPs. At the same time, the use of local wood energy can benefit both a user and the local economy. These effects can contribute to promote local economy and to achieve sustainability both globally and locally. Although the underutilization issue has not received much attention in sustainability discussions, it remains important. Underutilized issue is crucial as well as overutilization for sustainability of forest resources.

Acknowledgments: The authors thank Nishiwaga's Town Government and the Nishiwaga Forest Owners' Cooperative for providing the data needed for the analysis. This work was partly supported by the Japan Society for the Promotion of Science (JSPS), Grants-in-Aid for Scientific Research (KAKENHI, Grant Number: JP16H06202). 
Author Contributions: Takashi Hayashi is the main writer of this paper and conducted input-output analysis. Daisuke Sawauchi substantially contributed to the conception and writing of the paper, and performed linear programming analysis. Daisuke Kunii analyzed the data with geographic information system.

Conflicts of Interest: The authors declare no conflict of interest.

\section{References}

1. Fujiwara, M. Silviculture in Japan. In Forestry and the Forest Industry in Japan; Iwai, Y., Ed.; UBC Press: Vancouver, BC, Canada, 2002; pp. 10-23.

2. Forestry Agency. Compendium on Forest and Forestry. 2016. Available online: http://www.rinya.maff.go. jp/j/kikaku/toukei/attach/pdf/youran_mokuzi-7.pdf (accessed on 9 August 2017). (In Japanese)

3. Hasegawa, M.; Pulhin, J.M.; Inoue, M. Facing the challenge of social forestry in Japan: The case of reviving harmonious coexistence between forest and people in Okayama prefecture. Small Scale For. 2013, 12, 257-275. [CrossRef]

4. Forestry Agency. The Annual Report on Forest and Forestry in Japan Fiscal year 2014 (Summary). 2014. Available online: http://www.rinya.maff.go.jp/j/kikaku/hakusyo/26hakusyo/pdf/h26summary.pdf (accessed on 9 August 2017).

5. Energy Agency. Strategic Energy Plan. 2014. Available online: http://www.enecho.meti.go.jp/en/category/ others/basic_plan/pdf/4th_strategic_energy_plan.pdf (accessed on 9 August 2017).

6. Institute for Sustainable Energy Policies. Status of Renewable Energies in Japan (FY2016). 2017. Available online: http:/ / www.isep.or.jp/en/info/3343 (accessed on 27 September 2017).

7. Den Herder, M.; Kolström, M.; Lindner, M.; Suominen, T.; Tuomasjukka, D.; Pekkanen, M. Sustainability impact assessment on the production and use of different wood and fossil fuels employed for energy production in north Karelia, Finland. Energies 2012, 5, 4870-4891. [CrossRef]

8. Scarlat, N.; Dallemand, J.F.; Monforti-Ferrario, F.; Nita, V. The role of biomass and bioenergy in a future bioeconomy: Policies and facts. Environ. Dev. 2015, 15, 3-34. [CrossRef]

9. Kuunibe, N.; Issahaku, H.; Nkegbe, P.K. Wood Based Biomass Fuel Consumption in the Upper West Region of Ghana: Implications for Environmental Sustainability. J. Sustain. Dev. Stud. 2013, 3, 181-198.

10. Polagye, B.L.; Hodgson, K.T.; Malte, P.C. An economic analysis of bio-energy options using thinnings from overstocked forests. Biomass Bioenegy 2007, 31, 105-125. [CrossRef]

11. Neary, D.G.; Zieroth, E.J. Forest bioenergy system to reduce the hazard of wildfires: White Mountains, Arizona. Biomass Bioenegy 2007, 31, 638-645. [CrossRef]

12. Wolfe, R.; Moseley, C. Small-diameter log evaluation for value-added structural applications. For. Prod. J. 2001, 50, 48-58.

13. Sawauchi Village Government. Municipal Plan for Promoting Actions to Utilize Forest Biomass in Sawauchi; Sawauchi Village Government: Sawauchi, Japan, 2004. (In Japanese)

14. Nishizono, T.; Tanaka, K.; Hosoda, K.; Awaya, Y.; Oishi, Y. Effects of thinning and site productivity on culmination of stand growth: results from long term monitoring experiments in Japanese cedar (Cryptomeria japonica D. Don) forests in north-eastern Japan. J. For. Res. 2008, 13, 264-274. [CrossRef]

15. Aruga, K.; Yoshioka, T.; Sakurai, S. Long-term feasibility of timber and forest biomass resources at an intermediate and mountainous area-Balance of harvesting volumes using random search. J. Jpn. For. Eng. Soc. 2006, 21, 49-59, (In Japanese with English abstract).

16. Energy Agency. Survey on Price of Petroleum Products. 2017. Available online: http://www.enecho.meti. go.jp/statistics/petroleum_and_lpgas / p1007/results.html (accessed on 27 September 2017). (In Japanese)

17. Kunii, D.; Sawauchi, D.; Hayashi, T. Multi-dimensional assessment of environment and economy based on supply and demand matching of wood biomass: A case study of firewood use in households in Nishiwaga. Stud. Reg. Sci. 2015, 44, 481-493, (In Japanese with English abstract). [CrossRef]

18. Iwate Prefecture. Regional Input-Output Table of Iwate Prefecture. 2017. Available online: http:/ / www3.pref.iwate.jp/webdb / view / outside/s14Tokei/bnyaBtKekka.html?c=B0303\&r=I135\& searchJoken=B03\%3AB0303\%3AI135 (accessed on 27 September 2017). (In Japanese)

19. Ministry of Economy, Trade and Industry. Updated Input-Output Table. 2014. Available online: http://www.meti.go.jp/english/statistics/tyo/entyoio/index.html (accessed on 27 September 2017). 
20. Ministry of Internal Affairs and Communications. 2005 Input-Output Tables for Japan. 2009. Available online: http:/ / www.soumu.go.jp/english/dgpp_ss/data/io/io05.htm (accessed on 29 September 2017).

21. Sanchez-Garcia, S.; Canga, E.; Tolosana, E.; Majada, E. A spatial analysis of woodfuel based on WISDOM GIS methodology; Multiscale approach in Northern Spain. Appl. Energy 2015, 144, 193-203. [CrossRef]

22. Zhang, F.; Johnson, D.M.; Sutherland, J.W. A GIS-based method for identifying the optimal location for a facility to convert forest biomass to biofuel. Biomass Bioenergy 2011, 35, 3951-3961. [CrossRef]

23. Hossain, M.U.; Leu, S.; Poon, C.S. Sustainability analysis of pelletized bio-fuel derived from recycled wood product wastes in Hong Kong. J. Clean. Prod. 2016, 113, 400-410. [CrossRef]

24. Kim, M.; Song, H.B. Analysis of the global warming potential for wood waste recycling systems. J. Clean. Prod. 2014, 69, 199-207. [CrossRef]

25. Sacchelli, S.; Bernetti, I.; De Meo, I.; Fiori, L.; Paletto, A.; Zambelli, P.; Ciolli, M. Matching socio-economic and environmental efficiency of wood-residues energy chain: A partial equilibrium model for a case study in Alpine area. J. Clean. Prod. 2014, 66, 431-442. [CrossRef]

26. Valente, C.; Spinelli, R.; Hillring, B.G. LCA of environmental and socio-economic impacts related to wood energy production in alpine conditions: Valle di Fiemme (Italy). J. Clean. Prod. 2011, 19, 1931-1938. [CrossRef]

27. Ooba, M.; Hayashi, K.; Fujii, M.; Fujita, T.; Machimura, T.; Matsui, T. A long-term assessment of ecological-economic sustainability of wood biomass production in Japan. J. Clean. Prod. 2015, 88, 318-325. [CrossRef]

28. Paolotti, L.; Martino, G.; Marchini, A.; Pascolini, R.; Boggia, A. Economic and environmental evaluation of transporting imported pellet: A case study. Biomass Bioenergy 2015, 83, 340-353. [CrossRef]

29. Taskhiri, M.S.; Garbs, M.; Geldermann, J. Sustainable logistics network for wood flow considering cascade utilization. J. Clean. Prod. 2016, 110, 25-39. [CrossRef]

30. Yagi, K.; Nakata, T. Economic analysis on small-scale forest biomass gasification considering geographical resources distribution and technical characteristics. Biomass Bioenergy 2011, 35, 2883-2892. [CrossRef]

31. Cambero, C.; Sowlati, T. Assessment and optimization of forest biomass supply chains from economic, social and environmental perspectives-A review of literature. Renew. Sustain. Energy Rev. 2014, 36, 62-73. [CrossRef]

32. Meadows, J.; Coote, D.; Brown, M. The potential supply of biomass for energy from hardwood plantations in the Sunshine Coast Council region of south-east Queensland, Australia. Small Scale For. 2014, 13, 461-481. [CrossRef]

33. Ooba, M.; Fujita, T.; Mizuochi, M.; Fujii, M.; Machimura, T.; Matsu, T. Sustainable use of regional wood biomass in Kushida River basin, Japan. Waste Biomass Valoriz. 2012, 3, 425-433. [CrossRef]

34. Yoshioka, T.; Sakurai, R.; Aruga, K.; Sakai, H.; Kobayashi, H. A GIS-based analysis on the relationship between the annual available amount and the procurement cost of forest biomass in a mountainous region in Japan. Biomass Bioenergy 2011, 35, 4530-4537. [CrossRef]

35. Kinoshita, T.; Ohki, T.; Yamagata, Y. Woody biomass supply potential for thermal power plants in Japan. Appl. Energy 2010, 87, 2923-2927. [CrossRef]

36. Colantoni, A.; Delfanti, L.; Recanatesi, F.; Tolli, M.; Lord, R. Land use planning for utilizing biomass residues in Tuscia Romana (central Italy): Preliminary results of a multi criteria analysis to create an agro-energy district. Energy Policy 2016, 50, 125-133. [CrossRef]

37. Binder, C.R.; Hofer, C.; Wiek, A.; Scholz, R.W. Transition towards improved regional wood flows by integrating material flux analysis and agent analysis: The case of Appenzell Ausserrhoden, Switzerland. Ecol. Econ. 2004, 49, 1-17. [CrossRef]

38. Schlueter, A. Small-scale European forestry, an anticommons? Int. J. Commons 2008, 2, 248-268. [CrossRef]

39. Asai, M.; Langer, V.; Frederiksen, P.; Jacobsen, B.H. Livestock farmer perceptions of successful collaborative arrangements for manure exchange: A study in Denmark. Agric. Syst. 2014, 128, 55-65. [CrossRef]

40. Cavicchi, B.; Palmieri, S.; Odaldi, M. The influence of local governance: Effects on the sustainability of bioenergy innovation. Sustainability 2017, 9, 406. [CrossRef]

(C) 2017 by the authors. Licensee MDPI, Basel, Switzerland. This article is an open access article distributed under the terms and conditions of the Creative Commons Attribution (CC BY) license (http:// creativecommons.org/licenses/by/4.0/). 